\title{
MACHINE FOR THE EMANCIPATION OF CREATIVITY: ART PROJECT IN THE NEIGHBOURHOOD OF ESTRADA MILITAR DO ALTO DA DAMAIA
}

\author{
António Gorgel Pinto \\ CIAUD researcher, School of Architecture - University of Lisbon, Portugal, \\ gorgelpinto@gmail.com
}

\begin{abstract}
This paper addresses the concept of machine for the emancipation of creativity and its operation as part of a social art project developed in a slum from the city of Amadora, Portugal. The first part explores some fundamental concepts that inform the research, such as the notions of machine, emancipation and creativity. The following part is a detailed description of the artistic project and the analysis of its results.
\end{abstract}

Keywords: Social Art, Machine, Emancipation, Creativity, Participation, Multimedia.

\section{INTRODUCTION}

The purpose of the present research concerns the definition of a social art practice engaged with a specific community and focused in educational and participatory activities in the sphere of multimedia. Other objectives to reach are to promote the social cohesion between residents and the cultural revitalization of the place where they reside through the involvement of them with creative practices. Finally, it is intended to contribute to a reflection on the potential of contemporary visual arts for the development of practices simultaneously symbolic and fruitful to society.

The concept underlying this essay is titled machine for the emancipation of creativity, which is connected to a philosophical anthropology of the machine. The aim is to question the usefulness of machines as an aspect inside the notion of artificiality, the link among the domains of thought and functioning (Vengeon, 2009), as well as the relationship between technology and skill (Ingold, 2001). The arrangement of networked machines operate with the central objective of emancipating the creativity, which is understood not as a demiurgic output, but as a manifestation of humanity and universality, in which the entire social body can participate (Beuys apud Gomes, 2010).

Thus, some reflections and imagery are presented as a result from the machine of creativity emancipation, within the scope of a multimedia art project developed in a neighbourhood of Amadora, a Lisbon satellite city. Initially, the activities developed within the project have an educational participatory nature, being recorded by audiovisual media, and subsequently reproduced to represent the place and the local community.

The actions developed in the neighbourhood have a multimedia character, focusing on the fields of communication technologies, digital arts and photography, in particular computer lessons for adults and photography sessions for younger people. In this sense, the methodology and methods used will be presented, as well as the results obtained after the application of a survey to participants, and to other technicians and specialists involved in the project. 


\section{MACHINE FOR THE EMANCIPATION OF CREATIVITY}

The machine for the emancipation of creativity, in the context of the artistic social project developed in a disadvantaged neighborhood of Amadora, have an underlying set of essential aspects for its functionality. Firstly, the specific objective for the creativity stimulation of resident participants so that they release any preconceived ideas of inferiority, compared with other elements of society whose culture is more developed. Another key feature of the machine in question is the constitution of a previously set programme considering the objective. The programme is informed by concepts in the context of a philosophy of education sensitive to the notion of emancipation, as well as an aesthetic that, with social sensitivity, develops a series of actions and images of a participatory nature. Lastly, it should be noted that the creativity emancipation aims, as the second objective, to promote a reflection in society on the existence of other more efficient and humanist ways to resolve the problems belonging to the more degraded and deprived urban areas. In this sense, within the machine for the emancipation of creativity concept, the three notions in question will be analyzed, in particular - the machine, emancipation and creativity.

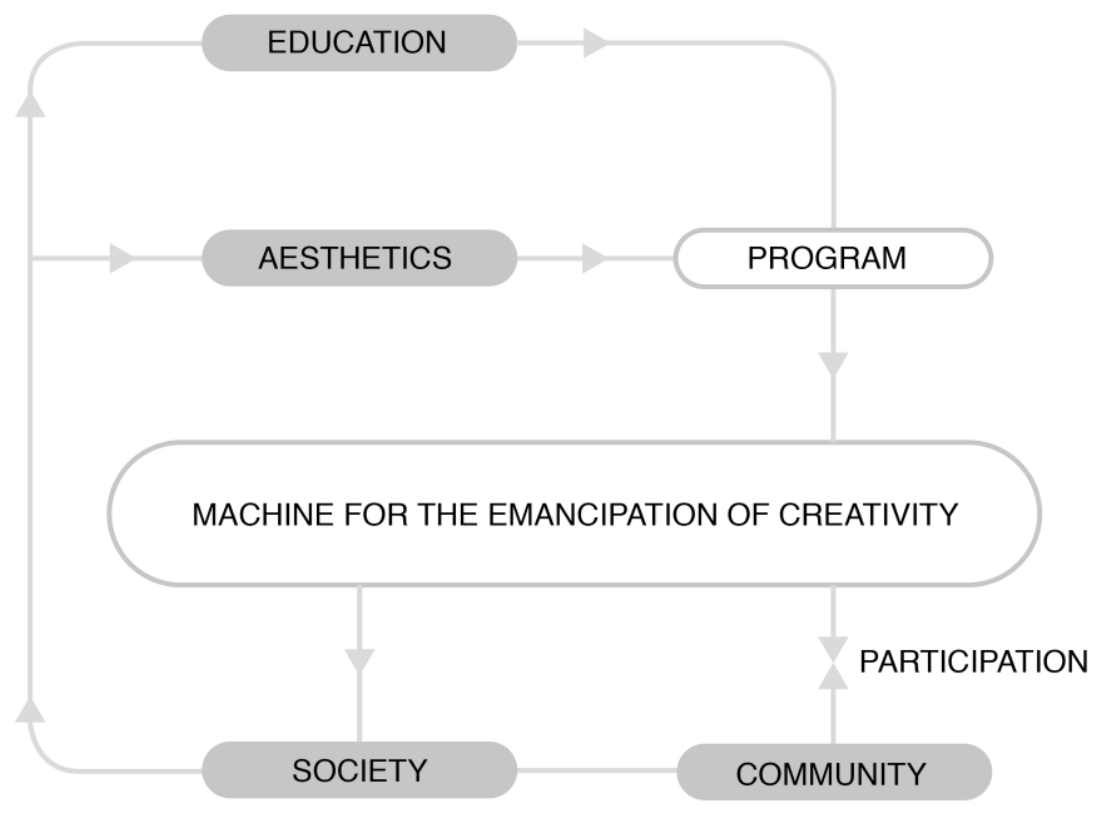

Fig. 1: Operational scheme of the machine for the emancipation of creativity (Gorgel Pinto, 2015).

\subsection{Machine}

The knowledge about the machine concept is quite advanced regarding the technological issues, but with little depth concerning the "links that connect mankind to artificiality", becoming fundamental the study on the machines usefulness, as an aspect inside a greater notion of artificiality, the connection between the fields of thought and functioning, as well as the formulation of models for the qualification of the devices (Vengeon, 2009, p.103).

This notion is related to the fact that there is no separation between human beings and their creations, since these produce transformations of various kinds, in particular those who are perceived in their way of thinking. This is a logic oriented to the development of technique, and the consequent production of concrete results that, reciprocally, has effects on the mind. In this sense, the technique is also a practice of reflection through which the human being determines his modes of action. "The man is an unfinished biological entity that only perseveres in the being due to a set of technical prostheses". In other words, the technique enables "survivorship, freedom and the humanization of the human being". All the artificiality resulting from technical processes created by man, in any area of knowledge, is a phenomenon of human nature (Vengeon, 2009, pp.103-104).

Considering the notions of art and technology, they evolved over time since they emerged and currently they still continue to develop. According to certain prospects, the two concepts are regarded as opposites, a thought that has roots since the 17th century, a time when the distinction had not yet been made between artists and craftsmen and where the various forms of artistic expression were referred to as techniques (Ingold, 2001, p. 17). 
From the etymological point of view, the art expression derives from the Latin ars, while technology comes from the Greek teknè. In the Greek period, as in the Roman, the two terms were used with the same purpose to describe a profession and a set of activities involving the production of objects. It should be noted that, at that time, people who made use of these professionals knew how to distinguish between the utility value and the aesthetic quality, being given greater importance to the skill of the performer (Burford, 1972, pp. 13-14). Since then, there has been a growing abstraction of various characteristics of intelligence, sensitivity and expression, which in turn are fundamental for the achievement of the various existing crafts that require a particular skill (Ingold, 2001, p. 17).

As a result of the evolution of art and technology concepts, the artefact came to be perceived as a mechanically produced copy, through a project or template, to the detriment of a skilled and sensitive interaction between the craftsman and the raw material. The wrong notion of the true essence of a craft, reduced to its technical specificities and to the mechanical implementation of a set of predefined operations, took root into society alongside the rise of art as a superior intellectual capacity in which "the creative exercise of the imagination" occurs. At the end of the 18th century, these facts led the understanding of society to a profound differentiation between the work of art and the artefact that guided some creative practices of useful nature, regardless of the expressive and sensitive characteristics, to a connotation with the field of technology (Coleman, 1988, p. 7 and Ingold, 2001, p. 18).

In the early 20th century there was also a change of meaning, regarding the concept of technology that has come to be understood as a set of rules and specifications related to the production apparatus, in which a practice is conceived, just as a plan determines a production. Previously, the technology was understood as a "framework of concepts and theory informing the scientific study of productive practices". Today, the notion of technology is cut off from most academic studies that focus on the various techniques, being merely restricted to the sphere of the worker in the development of his practice and in the implementation of its techniques. In this way, the worker became a mere operator "bound to the mechanical implementation of an objective system of productive forces, according to principles of functioning that remain indifferent to particular human aptitudes and sensibilities" (Ingold, 2001, p. 18).

Despite the common etymological origin and to the fact of art and technology being related concepts, it was settled in modern society a convention about the separation between both, which created the idea that technology is reduced to operation, while art is restricted to meaning. This incongruity, which drove away the notion of technology from the fields of culture and society, referring it to an "objective system of productive forces", led to a non-holistic understanding, particularly in the field of sociocultural anthropology. Conversely, art is socially and culturally framed by society (Ingold, 2001, pp. 18-19).

The problematic surrounding art and technique has its origin in none of the notions in particular, but in the separation between both. The idea that art belongs to an "ethereal" sphere of symbolic meanings emerged, situated on a superior level from the material domain, upon which technology seeks complete control. With this understanding, the western culture developed in the Greek and Roman periods, in particular the concepts of ars and teknè, which attributed a greater relevance to the practice and skill of the performer to the detriment of mechanical operating issues or of symbolic expression. Therefore, it makes sense to recover the Greek and Roman thought about the notion of ars and teknè, in such a way that they can be understood in a skill perspective and, thereby, contribute to the development of the various existing practices that humans create in several social and environmental contexts (Ingold, 2001, p. 20).

According to the artificiality notion in analysis, in which there is no division between the human being and the creations he develops through certain practical skills, it is possible to understand and clarify the concept of machine, an idea that represents the set of "artificial automatisms", without the compulsory need of an object to put them into practice. At the same time, it is also implied the separation between the machine and the human being, just being true that this presupposes a set of actions and functionalities. Therefore, it is possible to think about the human existence as a reality that goes hand in hand with artificiality, in which the man creates a context in accordance with "the forces who organize his spirit". Bearing in mind that the ability of human reflection, by itself, does not permit the creation of evolutionary conditions, the man systematically develops a series of automatisms to enhance both his physical actions as well as his thoughts (Vengeon, 2009, p. 104).

\subsection{Emancipation}

In the early 19th century Joseph Jacotot rehearsed a "dissonant" pedagogy in counter-cycle with the thought that was rooted in Western culture at that time. The aim of the existing status quo was the installation of an 
orderly society driving to progress and prevent the succession of crises. The implemented education at this time assumed a basic function in the more developed societies, where, on one hand, the elites were formed to give continuity to the government of society, and on the other, the less favored social classes were schooled to decrease the distance to the more educated classes (Rancière, 2002, pp.9-10).

In the course of the educational paradigm in force, the master assumed the position of guide in the conduct of the population shortly instructed to the values of modern society, just as the school was in charge of making the social inequalities smaller. In this context, Jacotot warned that the social model based on the referred pedagogy, parallel to the action of reducing cultural differences between classes, was actually repeating the same injustices. The intention of establishing equality from the assumption of inequality is a perverted perspective of the original objective. To achieve equality between social classes, it is essential to establish it as such from the beginning of the pedagogical action and not as the main purpose. The teaching must be sensitive to the vast amount of knowledge the "ignorant" have, as well as to the fact that the existence of social disparities is a pre-existing social dynamic that mustn't be enhanced in the development of learning. The master and the student should be placed in the same space of understanding from which initiates the exchange of knowledge. Thus, two antagonistic educational models remain: (1) an action of "brutalization" that confronts the student with his lack of capacity, at the same time as it tries to reduce it; and (2) an emancipatory teaching philosophy that is based on the respect for the students natural aptitudes, unknown or denied. As opposed to the "brutalization" attitude towards education, Jacotot advocated an "emancipation of minds" and an "equality of intelligences" as a means to achieve the ideal of equality (Rancière, 2002, pp. 10-11).

Although education increased throughout society, keeping the logic of progress and universality, it perpetuated the paradox of assuming inequality as a starting point to promote the equality in education. The society observed by Jacotot, among others of the same period, assumed the different social classes and their lack of equality, where education functioned as a form of valorization of the most disadvantaged, while transmitting the idea of belonging to the same social body. Compared to the period of Jacotot, the contemporary society feeds a certain perversity that grants equal conditions to all its members, "the same fruitions and freedoms", while maintaining "a vast school that has its savages to civilize and its students in difficulty to recover". Thus, the contemporary schools have taken on, exponentially, the mission of reducing inequalities, which, however, persist. It is important to emphasize that equality is an absolutely necessary value for social sustainability and requires agents to promote their permanent confirmation (Rancière, 2002, pp. 11-14).

Under the pedagogical action revealed by Jacotot, the master doesn't have the fundamental principle of explaining and disassembling the knowledge to make it simple and accessible to the young and ignorant spirits. The master depends on these to exert his authority and it is he who makes them feel unable to learn independently. Since that time education has followed on this path, relying on false dichotomies such as the erudite and the ignorant, the experienced and the inexperienced, among others, establishing the existence of two kinds of intelligences: an inferior and a superior one. The inferior intelligence, common to children and ignorant, is based on empirical experience, depending on the routine and usefulness. The superior intelligence, which comes from rationality, is related to the use of accurate and sensitive methodologies. What contributes to the "brutalization" of the disadvantaged social groups is the conviction of possessing a lower intelligence, which in turn crosses over the dominant class. We must keep in mind that intelligence is only confirmed when it is compared to a similar one, in terms of equality. This logic is systematized whenever a particular group is considered higher or lower than the other and in this way the "brutalization" is generalized (Rancière, 2002, pp. 16-20, 50-51).

The intelligence that drives all healthy children to the understanding of a new language is the result of the same learning process based on guessing, whose origin lies in the desire and willingness to match, "like responding to someone who speaks to you, and not the one who examines you, under the sign of equality". The existence of the master arises when the student does not have the required intensity, whose function is to guide his disciples until the entrance on the hermeneutical circle, from which they become able to move and leave when they so wish. In this sense, the relationship between the teacher and the students that is valued is the one that promotes a link between wills and not the submission of an intelligence to another. Thus, the sensitive issue lies in the initial statement of the master followed by a free exploration of the student who learns from another concrete intelligence, such as the book or the speech. Besides the will, the most sensitive issue for anyone who teaches resides in the ability to emancipate and, in this way, make possible the "Universal Education: learning anything, and relate to that thing all the rest, according to the principle that all men have equal intelligence". To those who seek to learn, the master must simply keep them in their course of exploration of new knowledge, even though they may deviate from the initial objective 
and find other know-how (Rancière, 2002, pp. 23-25, 30, 44). "Man is a will served by an intelligence" (Rancière apud Jacotot, 2002, p. 64)

\subsection{Creativity}

Although the creativity expression have emerged only in the Middle Ages, the concept dates back to the classical antiquity. Etymologically, the first expression of the family of words appeared in the 14th century, in the form of creating, from the Latin creatus. This was followed by the appearance of the adjective creative, in the second half of the 17th century, as well as the occurrence of the creativity noun, which appeared in the mid-19th century (Online Etymology Dictionary, n.d., n.p.).

Since its formulation, the creativity notion has mirrored different positions about its reason of existence and the way it affects the human being, either through demonstrations within the arts, or by the spontaneous and holistic way it manifests. The universal nature of creativity is a principle related with humanity, where being an artist belongs to the nature of all humans, with creative sensitivity, and not restricted to the genial character or to a rare aptitude of an individual in particular. The Renaissance artists, for example, manifested the interest in being fully sensitive and creative, both in artistic practice, writing, thought, and in every action in general. This was a different perspective of an artist from the one that came to be particularized and whose creativity is restricted to a single type of production (da Silva, 2009, pp. 76-77, 140).

It is important to emphasize the work and thought of Joseph Beuys an artist who advocated a universal notion of creativity, in which dialogue and language are means of expression that can have the forms of sculpture. The thought of each person is equivalent to the work of an artist, where it is essential to consider the possibilities of formal reasoning, just like the artist observes and reflects on the objects he produces. In this way, the art and the artistic education, in particular, must evolve beyond the usual disciplines and integrate other learning. Beuys argued that creativity is a consequence of the productive activity and a common characteristic to all human beings, saying that only art, conceived in this way, would have the ability to develop a freer society (Gomes, 2010, pp. 8-9, 21, 62, 122).

Thus, in accordance with Beuys principle "every man is an artist", creativity is not a faculty restricted to artistic production, being a characteristic that applies to the social body and that, consequently, allows a redefinition of the art territories. This broad notion of art or "social sculpture", as the artist references, argues that every human being has creative abilities that can be improved and that these potentiate their involvement in the transformation process of society. The language developed by Beuys had as a key feature a continuing need to communicate that led him to seek, persistently, several ways of transmission. The social sculpture, whose idea increases the sphere of action of the art object, considers creativity as a value of exchange, to the detriment of capital and profit, which have dominated the development of culture and which, according to Beuys, can lead society to paralysis (Gomes, 2010, pp. 8-9).

The association between the capital and creativity concepts is related to the Marxist notion of proletarian, which characterizes individuals whose ideology, in addition to repudiate capitalism, is based on the notions of universality, autonomy and emancipation of human beings as forms of total development of their essence. In its turn, this kind of evolution is based on two fundamental principles - the productive and social existence. Karl Marx conceives human beings through the concept of homo faber (human capacity in manufacturing utensils), where the ability to work and produce, as well as the awareness of these facts, is what characterizes humanity. In this way, the thought of Marx refers that these are qualities that transform the simple biological existence of human beings in a coexistence of social order. With the evolution of capitalism the proletariat remains "exploited and alienated". But while in the exploitation case this might be negotiated, as happens in the relationship between employers and unions, with regard to alienation it is a paradigm to be modified. The problem arises in the kind of compromise between the worker and the employer in the context of capitalist logic, as if both were in possession of goods with interest to the other, which can be traded. In other words, "the capitalist offers a salary and the worker his labor power". Herein lies the problem, because it is the workforce that characterizes the human being as a social and productive individual, being this the fundamental aspect to his universality (de Duve, 1988, pp. 52-53).

It was in this context that Beuys defined his concept of creativity, parallel to Marx's notion of workforce, which crosses the combination of creativity and culture with the relationship between workforce and political economy. This resulted in an intersubjective approach to which he gave the designation of "social sculpture", whose main pillar is the concept of creativity, a universal quality of human beings, where the aesthetics is also based. "Creativity is the potential of each and every one, and it precedes the division of labour: being the capacity to produce, in general". From this logic derives two unavoidable facts, that we are all artists and that art is not a professional activity. Creativity, beyond being an essential quality of human existence, is the 
"true capital" that allows the transaction of goods and services and represents a vital activity for the social body (de Duve, 1988, p. 57).

\section{SOCIAL ART PROJECT}

The social art project in question occurs within a disadvantaged neighbourhood in the urban centre of Amadora, named Bairro da Estrada Militar do Alto da Damaia (Fig. 2-3). The site is characterized by illegal construction and by the weak support of public entities to solve the existing problems, such as poverty, crime, among others. The area is mostly inhabited by immigrants and their descendants from Portuguesespeaking African countries, such as Angola, Cape Verde, Guinea Bissau and São Tomé and Principe.
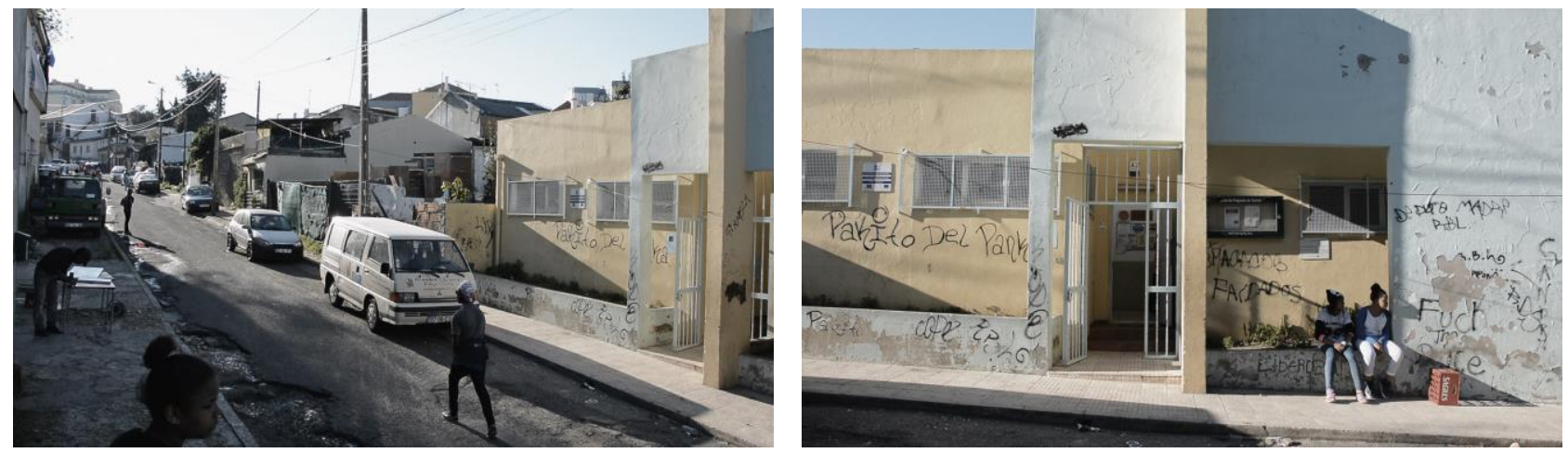

Fig. 2-3: Bairro da Estrada Militar do Alto da Damaia and Loja Social. Video frames (Gorgel Pinto, 2015).

The project was developed in partnership with a local association called Loja Social, in which two courses were created: in a first phase, a training course in the field of computer literacy, open to the participation of adults from the local population and, subsequently, another action on pinhole photography, which was destined to younger people (Fig. 4-5). The developed sessions, under each training, were restricted to a small number of participants, taking into account that logistical conditions were limited. The project counted with the collaboration of some trainees of a professional course in the field of multimedia, from a local high school, that gave assistance to the production.

This is a project-oriented practice that is developed in two phases, initially it works as a participatory educational system, to later introduce itself as a communicative space, emitting a series of messages about the place and the community where the actions take place. The content produced during the first phase was created in a training context, where both the people who received it as the people who knew more and shared their knowledge contributed with ideas for the elaboration of specific jobs. Although the educational were open to suggestions from participants and follow a course adapted to their own interests, it was previously defined a programme with concrete objectives.
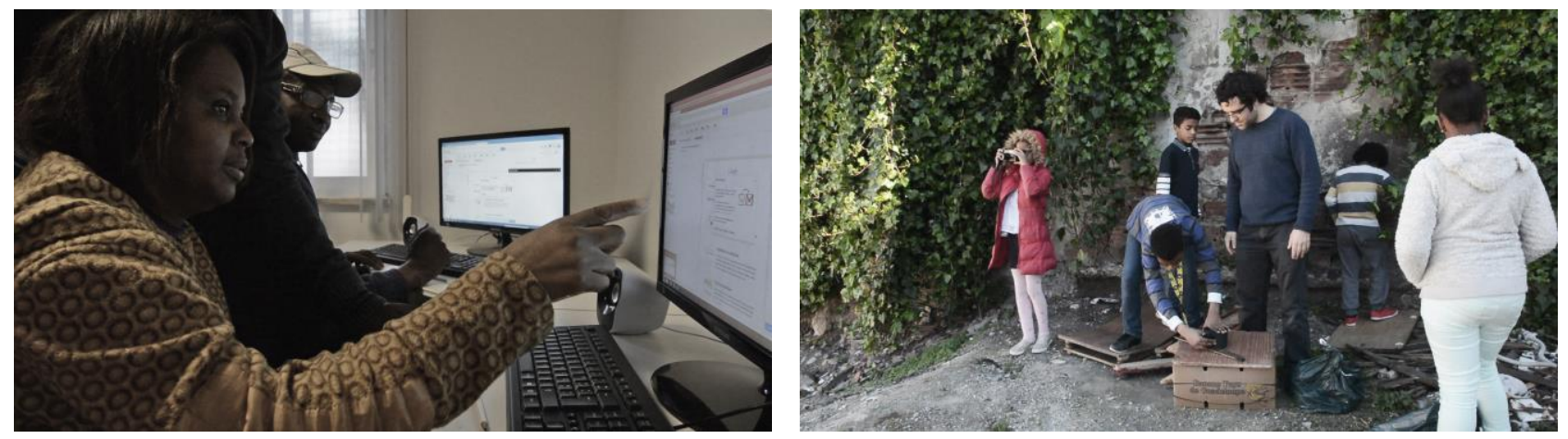

Fig. 4-5: Lessons for adults and workshop for youngsters. Video frames (Gorgel Pinto, 2015).

In the participatory sessions of the course, video footage, photographs, audio recordings and texts were collected, as well as other kind of references, to be aesthetically worked and integrate the final representation piece. With respect to the audio recordings, the interviews of some residents in the neighborhood stand out. It is intended that the set of multimedia pieces that represent the social art project, assume a contemplative character that confronts the viewer and refer him to a proper meaning in a space of numerous referents. At the same time, it is the illustration of a concrete social design project, with much focused methodologies and objectives with regard to the cultural appreciation of the community concerned. 
The presentation of the audiovisual content, produced during the educational actions, has been occurred in an isolated mode after the completion of each participatory process. The exhibition of all elements depicting the project, such as images, sounds, texts, among others, to the residents, as well as to the rest of the urban community, will take place at a specific location in the city of Amadora. It is intended, on one hand, to praise the culture of the people who inhabit these disadvantage neighborhoods, and on the other, to question two fundamental aspects of contemporary society: the civic responsibility in solving the problem of social inclusion and the potential of art and design in relation to the awareness to these kinds of difficulties. This phase is scheduled for the year 2016 and will be the conclusion of this particular social art project.

Bearing in mind the evaluation of the project, some interviews to the participants were conducted, as well as to other residents and employees from the social institution. Generally speaking, the people consulted considered the social support useful, since it values, directly, those who participate on the educational activities and, indirectly, the remaining residents. They also mentioned that this type of activity contributes to the neighborhood civic development, counter-cyclically with clandestine movements that regularly occur in place. With regard to the individuals involved in the learning, they also felt that the support received was useful for their daily life and it would be important to have the continuity of the activities. These people believe that participating in educational activities has positive effects on health, particularly in reasoning and memory. The younger participants, in the pinhole photography action (Fig. 6), reported that they would like to continue practicing photography in organized weekly sessions.

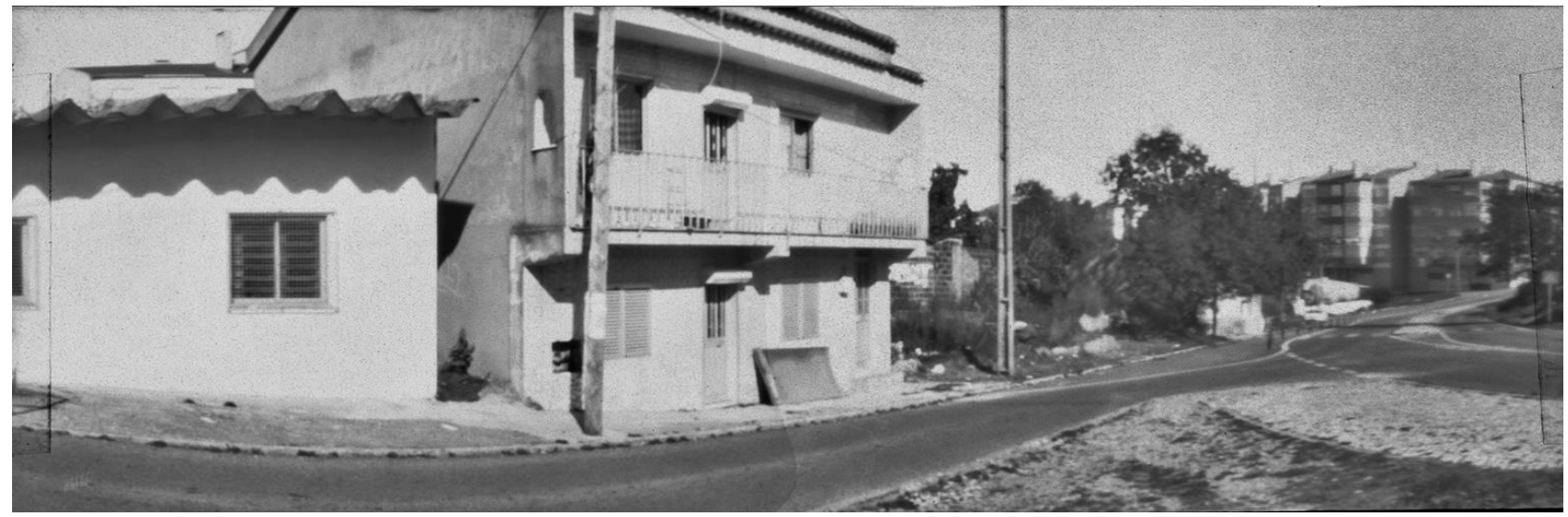

Fig. 6: Pinhole photography from the neighborhood (Gorgel Pinto, 2015).

Despite the social benefits of this project being obvious within the community, there is still the need to clarify some essential aspects for an in-depth evaluation, which will only be possible to understand after the final exhibition. Firstly, it is important to realize, among the residents, the effect of the symbolic reproductions produced in the activities course, or in other words, if they feel positively represented and encouraged to continue the involvement with other initiatives. At the same time, it will be fundamental sounding out the rest of the urban community to determine whether these feel more sensitized to this problem, in particular to the civic duty of society in solving problems such as social inclusion and the responsibility of art and design in relation to the awareness to these kind of difficulties.

\section{CONCLUSION}

One of the objectives of this research is to emphasize the visual arts vocation for a particular perception with regard to the various issues that concern the common good. The articulation between the ethical and aesthetic sensibilities acquires a specific dimension with potential to interpret and communicate critical and constructive viewpoints about social problematic. This type of sensory knowledge, subject to reflection and reproduction, produces a fundamental effect for the development of intersubjectivity.

This notion of art, symbolic and prolific at the same time, is essential for the development of the art project developed in the neighborhood of Estrada Militar do Alto da Damaia. It is a holistic practice that explores various dimensions of knowledge with a view to the sustainable development of the social tissue. In this context, the creation and use of the machine for the emancipation of creativity concept, aims at improving the socio-cultural situation of the community concerned. The adopted methodology of participatory nature is intended to promote educational activities in order to emancipate the creativity of the people involved and valuing them through their representation. It should be noted that the mechanism found in this research could be applied to other urban contexts in order to contribute to solving similar problems. 
The recognition of the existing creative energy in this type of disadvantaged residential areas is indispensable for a more inclusive society, in which is focused the equality of intelligences in comparison with citizens of urban areas that are socially and culturally privileged. This ability to integrate, value and inform all citizens, through a multimedia art practice with social sensitivity, is a procedure that should be generalized in society. In this sense, it is intended to continue the research and the experimental work through the involvement with other urban neighborhoods of Lisbon.

\section{ACKNOWLEDGEMENT}

This research was financially supported by: CIAUD - Architecture, Urbanism and Design Research Centre; FCT - Foundation of Science and Technology.

\section{REFERENCE LIST}

Burford, A. (1972). Craftsmen in Greek and Roman Society. Cornell University Press.

Coleman, R. (1988). The Art of Work: An Epitaph to Skill. Pluto Press.

Da Silva, A. (2009). Citações e pensamentos de Agostinho da Silva. Casa das Letras.

De Duve, T. (1988). Joseph Beuys, or the Last of the Proletarians. October, v.45. The MIT Press.

Gomes, J. do C. (2010). Beuys, Homem-Arena. Cada Homem Um Artista. 7 Nós.

Ingold, T. (2001). "Beyond Art and Technology: The Anthropology of Skill". Anthropological Perspectives on Technology. Ed. by M. B. Schiffer. UNM Press, pp. 17-31.

Online etymology dictionary [WWW Document], n.d. $\quad$ URL http://www.etymonline.com/index.php?term=design (accessed 1.10.14).

Rancière, J. (2002). "O mestre ignorante: cinco lições sobre a emancipação intellectual". Autêntica.

Vengeon, F. (2009). "Defesa de uma Antropologia Filosófica da Máquina. Remate de Males", v.29, n.1: Tecnologia das Letras. Ed. by F. A. Durão e M. Siscar. Unicamp. 